\title{
Common fixed points for multivalued mappings in ordered partial metric space
}

\author{
E. Nazari ${ }^{1 *}$, N. Mohitazar ${ }^{2}$ \\ ${ }^{1,2}$ Department of Mathematics, Tafresh University, Tafresh, Iran \\ *nazari.esmaeil@gmail.com
}

Copyright (C)2015 E. Nazari and N. Mohitazar. This is an open access article distributed under the Creative Commons Attribution License, which permits unrestricted use, distribution, and reproduction in any medium, provided the original work is properly cited.

\begin{abstract}
In the present work, we establish some common fixed point results for a pair of weakly isotone increasing set-valued mappings in a ordered complete partial metric space.
\end{abstract}

Keywords: Multivalued operators, Ordered complete partially metric space, Common fixed point.

\section{Introduction}

The notion of partial metric is one of the most useful and interesting generalizations of the classical concept of metric. The partial metric spaces were introduced in 1994 by Matthews [10]. Based on this notion, Matthews [10], Oltra and Valero [13], Ilic et al. [7, 8], Kadelburg et al. [9], Di Bari et al. [3], Hemant Kumar Nashine et al. [11] obtained some very interesting fixed point theorems for mappings satisfying different contractive conditions.

Very recently Hong in [6] introduced the concepts of approximative values, This definition is a very useful tool for proving the existence of a fixed point of a multivalued operator in an ordered metric space. In [5] Erduran extend the concept of approximative values in partial metric space, and he proved some fixed point for multivalued mappings.

In this paper, we obtain some new common fixed point theorems for a pair of multivalued mappings in ordered partial metric spaces. Our results are ordered version generalization of the results of Hong [6] and Erduran [5].

Definition 1.1 [10] A partial metric on a nonempty set $X$ is a mapping $p: X \times X \rightarrow R^{+}$such that for all $x, y, z \in X$, the following conditions are satisfied:

(i) $x=y \Leftrightarrow p(x, x)=p(x, y)=p(y, y)$,

(ii) $p(x, x) \leq p(x, y)$,

(iii) $p(x, y)=p(y, x)$,

(iv) $p(x, y) \leq p(x, z)+p(z, y)-p(z, z)$.

A partial metric space is a pair $(X, p)$ such that $\mathrm{X}$ is a nonempty set and $p$ is a partial metric on $\mathrm{X}$. Each partial metric $p$ on $\mathrm{X}$ generates a $T_{0}$ topology $\tau_{p}$ on $\mathrm{X}$ which has as a base, the family of open $p$-balls $\left\{B_{p}(x, \varepsilon), x \in X, \varepsilon>0\right\}$, where

$$
B_{p}(x, \varepsilon)=\{y \in X: p(x, y)<p(x, x)+\varepsilon\},
$$

for all $x \in X$ and $\varepsilon>0$.

If $p$ is a partial metric on $\mathrm{X}$, then the mapping $d_{p}: X \times X \rightarrow R^{+}$given by 


$$
d_{p}(x, y)=2 p(x, y)-p(x, x)-p(y, y)
$$

is a metric on $\mathrm{X}$.

Definition 1.2 [12] Let $(X, p)$ be a partial metric space. Then a sequence $\left\{x_{n}\right\}$ in $X$ called

(i) convergent if there exists a point $x \in X$ such that $p(x, x)=\lim _{n \rightarrow \infty} p\left(x_{n}, x\right)$,

(ii) Cauchy sequence if there exists (and is finite) $\lim _{n, m \rightarrow \infty} p\left(x_{n}, x_{m}\right)$.

Definition 1.3 [12] A partial metric space $(X, p)$ is said to be complete if every Cauchy sequence $\left\{x_{n}\right\}$ in $X$ converges, with respect to $\tau_{p}$, to a point $x \in X$ such that $p(x, x)=\lim _{n, m \rightarrow \infty} p\left(x_{n}, x_{m}\right)$.

Lemma 1.4 [12] Let $(X, p)$ be a partial metric space. Then

(i) $\left\{x_{n}\right\}$ is a Cauchy sequence in $(X, p)$ if and only if it is a Cauchy sequence in the metric space $\left(X, d_{p}\right)$,

(ii) $(X, p)$ is complete if and only if the metric space $\left(X, d_{p}\right)$ is complete. Furthermore, $\lim _{n \rightarrow \infty} d_{p}\left(x_{n}, x\right)=0$ if and only if $p(x, x)=\lim _{n \rightarrow \infty} p\left(x_{n}, x\right)=\lim _{n, m \rightarrow \infty} p\left(x_{n}, x_{m}\right)$.

Let $C B^{p}(X)$ be a family of all nonempty, closed and bounded subsets of the partial metric space $(X, p)$. Note that closed-ness is taken from $\left(X, \tau_{p}\right)\left(\tau_{p}\right.$ is the topology induced by $\left.\mathrm{p}\right)$ and bounded-ness is given as follows: $A$, is a bounded subset in $(X, p)$ if there exist $x_{0} \in X$ and $M \geq 0$ such that for all $a \in A$, we have $a \in B_{p}\left(x_{0}, M\right)$, that is, $p\left(x_{0}, a\right)<p(a, a)+M$.

For $A, B \in C B^{p}(X)$ and $x \in X$, we defined

$$
\begin{gathered}
p(x, A)=\inf \{p(x, y): y \in A\}, \\
\delta_{p}(A, B)=\sup \{p(a, B): a \in A\}, \\
\delta_{p}(B, A)=\sup \{p(A, b): b \in B\},
\end{gathered}
$$

and

$$
H_{p}(A, B)=\max \left\{\delta_{p}(A, B), \delta_{p}(B, A)\right\} .
$$

It is immediate to check that $p(x, A)=0$ implies that $d_{p}(x, A)=0$, where $d_{p}(x, A)=\inf \left\{d_{p}(x, a): a \in A\right\}$.

Corollary 1.5 [1] Let $(X, p)$ be a partial metric space and $A$ be any nonempty set in $(X, p)$, then a $\in \bar{A}$ if and only if $p(a, A)=p(a, a)$, where $\bar{A}$ denotes the closure of $A$ with respect to the partial metric $p$. Note that $A$ is closed in $(X, p)$ if and only if $A=\bar{A}$.

Proposition 1.6 [2] Let $(X, p)$ be a partial metric space. For all $A, B, C \in C B^{p}(X)$, we have

$\left(h_{1}\right) \quad H_{p}(A, A) \leq H_{p}(A, B)$,

$\left(h_{2}\right) \quad H_{p}(A, B)=H_{p}(B, A)$,

$\left(h_{3}\right) \quad H_{p}(A, B) \leq H_{p}(A, C)+H_{p}(C, B)-\inf _{c \in C} p(c, c)$,

$\left(h_{4}\right) H_{p}(A, B)=0 \Rightarrow A=B$.

The mapping $H_{p}: C B^{p}(X) \times C B^{p}(X) \rightarrow[0,+\infty)$, is called the partial Hausdorff metric induced by $p$. It is easy to show that any Hausdorff metric is a partial Hausdorff metric. The converse is not true see Example 2.6 in [2].

Definition 1.7 Let $X$ be a nonempty set. Then $(X, p)$ is called an ordered partial metric space if:

(i) $(X ; p)$ is a partial metric space,

(ii) $(X ; \preceq)$ is a partially ordered set.

Let $(X ; \preceq)$ be a partially ordered set. Then $x, y \in X$ are called comparable if $x \preceq y$ or $y \preceq x$ holds.

Definition $1.8[6]$. Let $A$ and $B$ be two nonempty subsets of a ordered set $(X ; \preceq)$. The relation $\preceq_{2}$ between two nonempty subsets $A$ and $B$ of $X$ is defined as follows:

$A \preceq{ }_{2} B$; if $a \preceq b$ for every $a \in A$ and every $b \in B$ : 
Definition 1.9 Let $(X ; \preceq)$ be a partially ordered set. Two maps $S ; T: X \rightarrow 2^{X}$ are said to be weakly isotone increasing if for any $x \in X$ we have $S x \preceq_{2}$ Ty for all $y \in S x$ and $T x \preceq_{2}$ Sy for all $y \in T x$.

Note that, in particular, single-valued mappings $T ; S: X \rightarrow X$ are weakly isotone increasing [4] if $S x \preceq T S x$ and $T x \preceq S T x$ hold for each $x \in X$.

Definition 1.10 An ordered partial metric space is said to have a sequential limit comparison property if for every nondecreasing sequence (nonincreasing sequence) $\left\{x_{n}\right\}$ in $X$ such that $x_{n} \rightarrow x$ implies that $x_{n} \leq x$ ( $\left.x \leq x_{n}\right)$, respectively.

Definition 1.11 Let $X$ be a ordered partial metric space. A subset $D \subseteq X$ is said to be approximative if the multivalued mapping

$$
P_{D}(x)=\{y \in D: p(x, y)=p(D, x)\}, \quad \forall x \in X
$$

has nonempty values.

A set-valued operator $T$ is said to have approximate values in $X$ if $T x$ is an approximation for each $x \in X$.

Definition 1.12 Let $N \in(0, \infty]$. Denote by $\Psi$ the set of functions $\psi:[0 ; N) \rightarrow R$ satisfying:

(i) $\psi(0)=0$ and $\psi(t)>0$ for each $t \in(0, N)$

(ii) $\psi$ is nondecreasing on $[0, N)$

(iii) $\psi$ is continuous.

(iv) $\limsup _{s \rightarrow 0} \frac{s}{\psi(s)}<\infty$.

Definition 1.13 Let $N \in(0 ; \infty]$. Denote by $\Phi$ the set of functions $\varphi:[0 ; N) \rightarrow[0 ; \infty)$ satisfying:

(i): $\varphi$ lower semi-continuous.

(ii): $\varphi(t)=0$ if and only if $t=0$.

(iii): For any sequence $\left\{r_{n}\right\}$ with $\lim _{n \rightarrow \infty} r_{n}=0$, there exist $a \in(0,1)$ and $n_{0} \in N$ such that $\varphi\left(r_{n}\right) \geq$ ar $r_{n}$ for each $n \geq n_{0}$.

In what follows, we will denote $\Theta$ the set of all functions $\theta:[0,+\infty)^{4} \rightarrow[0,+\infty)$ with the following property

1) $\theta$ is continuous,

2) $\theta$ is nondecreasing in third and forth components,

3) $\theta\left(t_{1}, t_{2}, t_{3}, t_{4}\right)=0 \Leftrightarrow t_{1} t_{2} t_{3} t_{4}=0$.

Example 1.14 The following functions belong to $\Theta$ :

(1) $\theta\left(t_{1}, t_{2}, t_{3}, t_{4}\right)=L \min \left\{t_{1}, t_{2}, t_{3}, t_{4}\right\}, L>0$

(2) $\theta\left(t_{1}, t_{2}, t_{3}, t_{4}\right)=t_{1} t_{2} t_{3} t_{4}$,

(3) $\theta\left(t_{1}, t_{2}, t_{3}, t_{4}\right)=\ln \left(1+t_{1} t_{2} t_{3} t_{4}\right)$,

(4) $\theta\left(t_{1}, t_{2}, t_{3}, t_{4}\right)=\exp \left(t_{1} t_{2} t_{3} t_{4}\right)-1$.

Let $T, S: X \rightarrow 2^{X}$ are two mappings, we denote,

$$
M(x, y)=\operatorname{Max}\left\{p(x, y), p(x, T x), p(y, S y), \frac{1}{2}[p(y, T x)+p(x, S y)]\right\}
$$

Now, we introduce the following definition.

Definition 1.15 Let $X$ be an ordered partial metric space and let $\rho=\sup \{p(x, y): x, y \in X\}$. Set $N=\rho$ if $\rho=\infty$ and $N>\rho$ if $\rho<\infty$. We say that two mappings $T, S: X \rightarrow 2^{X}$ are generalized $(\psi, \varphi, \theta)$ - contraction if,

$\psi\left(H_{p}(T x, S y)\right) \leq \psi(M(x, y))-\varphi(\psi(M(x, y)))+\theta(p(x, T x), p(y, S y), p(y, T x)-p(y, y), p(x, S y)-p(x, x))$

for all $x, y \in X$, with $x$ and $y$ comparable and, $\psi \in \Psi, \varphi \in \Phi$ and $\theta \in \Theta$. 


\section{Main results}

In this section we prove common fixed point theorems for a pair of multivalued mappings in a ordered complete partial metric space.

Theorem 2.1 Let $X$ be a complete ordered partial metric space with the limit comparison property. Suppose that $T, S: X \rightarrow 2^{X}$ are generalized $(\psi, \varphi, \theta)$-contractive mappings with approximative property. Let $S$ and $T$ are weakly isotone increasing and there exists an $x_{0} \in X$ such that $\left\{x_{0}\right\} \preceq_{2} T x_{0}$. Then $T, S$ have a common fixed point $x \in X$, such that $p(x, x)=0$.

Proof: First of all we show that, if $x$ be a fixed point of $T$ such that $p(x, x)=0$ it is a common fixed point of $T$ and $S$. Indeed,

$$
\begin{aligned}
\psi(p(S x, x)) & \leq \psi\left(H_{p}(S x, T x)\right) \\
& \leq \psi(M(x, x))-\varphi(\psi(M(x, x))) \\
& +\theta(p(x, T x), p(x, S x), p(x, T x)-p(x, x), p(x, S x)-p(x, x)) \\
& =\psi(M(x, x))-\varphi(\psi(M(x, x)))+\theta(p(x, T x), p(x, S x), 0,(x, S x)-p(x, x)) \\
& =\psi(M(x, x))-\varphi(\psi(M(x, x)))
\end{aligned}
$$

where

$$
\begin{aligned}
M(x, x) & =\operatorname{Max}\left\{p(x, x), p(x, T x), p(x, S x), \frac{p(x, S x)+p(x, T x)}{2}\right\} \\
& \leq \operatorname{Max}\left\{p(x, x), p(x, x), p(x, S x), \frac{p(x, S x)+p(x, x)}{2}\right\} \\
& =d(x, S x) .
\end{aligned}
$$

thus by (1), we have

$$
\begin{aligned}
\psi(p(S x, x)) & \leq \psi(p(x, S x))-\varphi(\psi(p(S x, x))) \\
& +\theta(p(x, S x), p(x, x), p(x, S x), p(x, x)) \\
& =\psi(p(x, S x))-\varphi(\psi(p(S x, x)))
\end{aligned}
$$

This implies that, $\varphi(\psi(p(S x, x)))=0$ and hence $p(S x, x)=0$. Since $S x$ is approximative property, therefore there exist $y \in P_{S x}(x)$ such that $p(y, x)=0$ i.e, $y=x$. Thus $x \in S x$.

Let $x_{0} \in X$, if $x_{0} \in T x_{0}$ our proof is complete. Otherwise, from the fact that $T x_{0}$ has approximation property it follows there exists $x_{1} \in T x_{0}$, with $x_{1} \neq x_{0}$ such that

$$
p\left(x_{0}, x_{1}\right)=\inf _{x \in T x_{0}} p\left(x, x_{0}\right)=p\left(T x_{0}, x_{0}\right) .
$$

Again if $x_{1} \in S x_{1}$ our proof is complete. Otherwise, since $S x_{1}$ has approximation property it follows there exist $x_{2} \in S x_{1}$ with $x_{2} \neq x_{1}$ such that

$$
p\left(x_{1}, x_{2}\right)=\inf _{x \in S x_{1}} p\left(x, x_{1}\right)=p\left(S x_{1}, x_{1}\right) .
$$

By induction and using approximative property, we can find in this way a sequence $\left\{x_{n}\right\}$ in $X$, such that $x_{2 n+1} \in$ $T x_{2 n}$ and

$$
p\left(x_{2 n+1}, x_{2 n}\right)=p\left(T x_{2 n}, x_{2 n}\right),
$$

and $x_{2 n+2} \in S x_{2 n+1}$, with

$$
p\left(x_{2 n+2}, x_{2 n+1}\right)=p\left(S x_{2 n+1}, x_{2 n+1}\right) .
$$

On the other hand

$$
\begin{gathered}
p\left(T x_{2 n}, x_{2 n}\right) \leq \sup _{x \in S x_{2 n-1}} p\left(T x_{2 n}, x\right) \\
\leq H_{p}\left(T x_{2 n}, S x_{2 n-1}\right) .
\end{gathered}
$$


Therefore

$p\left(x_{2 n+1}, x_{2 n}\right) \leq H_{p}\left(T x_{2 n}, S x_{2 n-1}\right)$.

Similarly we can show that

$p\left(x_{2 n+2}, x_{2 n+1}\right) \leq H_{p}\left(S x_{2 n+1}, T x_{2 n}\right)$.

On the other hand since $x_{0} \preceq_{2} T x_{0}$, and $x_{1} \in T x_{0}$, we have $x_{0} \preceq x_{1}$. Now since $T$ and $S$ are isotone increasing we have $T x_{0} \preceq_{2} S y$ for all $y \in T x_{0}$, thus $T x_{0} \preceq_{2} S x_{1}$. In particular, $x_{1} \preceq x_{2}$. By continuing this process we can show that

$$
x_{1} \preceq x_{2} \preceq \ldots \preceq x_{n} \preceq x_{n+1} \preceq \ldots
$$

Now we show that $\lim _{n \rightarrow \infty} p\left(x_{n+1}, x_{n}\right)=0$.

Since $\psi$ is nondecreasing, from (2) and the fact that $T$ and $S$ are generalized $(\psi, \varphi, \theta)$-contraction we have,

$$
\begin{aligned}
\psi\left(p\left(x_{2 n+1}, x_{2 n}\right)\right) & \leq \psi\left(H_{p}\left(T x_{2 n}, S x_{2 n-1}\right)\right) \\
& \leq \psi\left(M\left(x_{2 n}, x_{2 n-1}\right)\right)-\varphi\left(\psi\left(M\left(x_{2 n}, x_{2 n-1}\right)\right)\right) \\
& +\theta\left(p\left(x_{2 n}, T x_{2 n}\right), p\left(x_{2 n-1}, S x_{2 n-1}\right), p\left(x_{2 n}, S x_{2 n-1}\right)-p\left(x_{2 n}, x_{2 n}\right)\right. \\
& , p\left(x_{2 n+1}, T x_{2 n}\right)-p\left(x_{2 n-1}, x_{2 n-1}\right) \\
& \leq \psi\left(M\left(x_{2 n}, x_{2 n-1}\right)\right)-\varphi\left(\psi\left(M\left(x_{2 n}, x_{2 n-1}\right)\right)\right) \\
& +\theta\left(p\left(x_{2 n+1}, x_{2 n}\right), p\left(x_{2 n-1}, x_{2 n}\right), p\left(x_{2 n}, x_{2 n}\right)-p\left(x_{2 n}, x_{2 n}\right)\right. \\
& , p\left(x_{2 n+1}, x_{2 n+1}\right)-p\left(x_{2 n-1}, x_{2 n-1}\right) \\
& \leq \psi\left(M\left(x_{2 n}, x_{2 n-1}\right)\right)-\varphi\left(\psi\left(M\left(x_{2 n}, x_{2 n-1}\right)\right)\right)
\end{aligned}
$$

where

$$
\begin{aligned}
M\left(x_{2 n}, x_{2 n-1}\right) & =\operatorname{Max}\left\{p\left(x_{2 n}, x_{2 n-1}\right), p\left(x_{2 n}, T x_{2 n}\right), p\left(x_{2 n-1}, S x_{2 n-1}\right)\right. \\
& \left.\frac{p\left(x_{2 n-1}, T x_{2 n}\right)+p\left(x_{2 n}, S x_{2 n-1}\right)}{2}\right\} \\
& \leq \operatorname{Max}\left\{p\left(x_{2 n}, x_{2 n-1}\right), p\left(x_{2 n}, x_{2 n+1}\right), p\left(x_{2 n-1}, x_{2 n}\right), \frac{p\left(x_{2 n-1}, x_{2 n+1}\right)+p\left(x_{2 n}, x_{2 n}\right)}{2}\right\} \\
& \leq \operatorname{Max}\left\{p\left(x_{2 n}, x_{2 n-1}\right), p\left(x_{2 n}, x_{2 n+1}\right), p\left(x_{2 n-1}, x_{2 n}\right), \frac{p\left(x_{2 n-1}, x_{2 n}\right)+p\left(x_{2 n}, x_{2 n+1}\right)}{2}\right\} \\
& =\operatorname{Max}\left\{p\left(x_{2 n-1}, x_{2 n}\right), p\left(x_{2 n}, x_{2 n+1}\right)\right\} .
\end{aligned}
$$

If $\operatorname{Max}\left\{p\left(x_{2 n-1}, x_{2 n}\right), p\left(x_{2 n}, x_{2 n+1}\right)\right\}=p\left(x_{2 n}, x_{2 n+1}\right)$, then by (4) we have

$$
\begin{gathered}
\psi\left(p\left(x_{2 n+1}, x_{2 n}\right)\right)<\psi\left(M\left(x_{2 n}, x_{2 n-1}\right)\right) \\
<\psi\left(p\left(x_{2 n+1}, x_{2 n}\right)\right),
\end{gathered}
$$

which gives a contradiction. Therefore we have $p\left(x_{2 n}, x_{2 n-1}\right) \leq M\left(x_{2 n}, x_{2 n-1}\right) \leq p\left(x_{2 n}, x_{2 n-1}\right)$, and so $M\left(x_{2 n}, x_{2 n-1}\right)=$ $p\left(x_{2 n}, x_{2 n-1}\right)$. Now by using (4) we have

$\psi\left(p\left(x_{2 n+1}, x_{2 n}\right)\right) \leq \psi\left(p\left(x_{2 n}, x_{2 n-1}\right)\right)-\varphi\left(\psi\left(p\left(x_{2 n}, x_{2 n-1}\right)\right)\right) \leq \psi\left(p\left(x_{2 n}, x_{2 n-1}\right)\right)$.

Take the same proceeding we have,

$\psi\left(p\left(x_{2 n+1}, x_{2 n+2}\right)\right) \leq \psi\left(p\left(x_{2 n}, x_{2 n+1}\right)\right)-\varphi\left(\psi\left(p\left(x_{2 n}, x_{2 n+1}\right)\right)\right) \leq \psi\left(p\left(x_{2 n}, x_{2 n+1}\right)\right)$.

By (5),(6), we conclude that

$p\left(x_{n+1}, x_{n}\right) \leq p\left(x_{n}, x_{n-1}\right)$

for all $n \in N$.

Therefore, the sequence $\left\{p\left(x_{n}, x_{n+1}\right)\right\}$ is a nonnegative non-increasing and hence there exists $r \geq 0$ such that

$$
\lim _{n \rightarrow \infty} p\left(x_{n+1}, x_{n}\right)=r
$$


Since $\varphi$ is l.s.c,

$$
\begin{gathered}
\varphi(\psi(r)) \leq \liminf _{n \rightarrow \infty} \varphi\left(\psi\left(p\left(x_{n}, x_{n-1}\right)\right)\right) \\
\leq \liminf _{n \rightarrow \infty} \varphi\left(\psi\left(p\left(x_{2 n-1}, x_{2 n}\right)\right)\right)
\end{gathered}
$$

Hence by (5),we have

$$
\psi(r) \leq \psi(r)-\varphi(\psi(r))
$$

and so $\varphi(\psi(r))=0$. Hence $r=0$.

In what follows we will show that $\left\{x_{n}\right\}$ is a cauchy sequence. Since $\lim _{n \rightarrow \infty} p\left(x_{n}, x_{n+1}\right)=0$, from assumption (iii) of $\varphi$ there exists $0<\alpha<1$ and $n_{0} \in N$ such that

$$
\varphi\left(\psi\left(p\left(x_{n}, x_{n-1}\right)\right)\right) \geq \alpha \psi\left(p\left(x_{n}, x_{n-1}\right)\right) \quad \text { for all } n \geq n_{0} .
$$

On the hand for all $n \geq n_{0}$, from (2) or (3)) we have,

$$
\begin{gathered}
\psi\left(p\left(x_{n+1}, x_{n}\right)\right) \leq \psi\left(H _ { p } ( T x _ { n } , S x _ { n - 1 } ) \left(\operatorname{or} \psi\left(H_{p}\left(T x_{n-1}, S x_{n}\right)\right)\right.\right. \\
\leq \psi\left(M\left(x_{n}, x_{n-1}\right)\right)-\varphi\left(\psi\left(M\left(x_{n}, x_{n-1}\right)\right)\right) \\
\leq(1-\alpha) \psi\left(M\left(x_{n}, x_{n-1}\right)\right)=(1-\alpha) \psi\left(p\left(x_{n}, x_{n-1}\right)\right) .
\end{gathered}
$$

Thus for any $k>n_{0}$ we have

$$
\psi\left(p\left(x_{k}, x_{k-1}\right)\right) \leq(1-a) \psi\left(p\left(x_{k-1}, x_{k-2}\right)\right) \leq \ldots \leq(1-a)^{k-n} \psi\left(p\left(x_{n_{0}}, x_{n_{0}-1}\right)\right) .
$$

Therefore

$$
\sum_{1}^{\infty} \psi\left(p\left(x_{n}, x_{n+1}\right)\right) \leq \sum_{1}^{n_{0}} \psi\left(p\left(x_{n}, x_{n+1}\right)\right)+\sum_{n_{0}}^{\infty}(1-\alpha)^{k-n_{0}} \psi\left(p\left(x_{n_{0}}, x_{n_{0}+1}\right)\right)<\infty .
$$

Since,

$$
\limsup _{n \rightarrow \infty} \frac{p\left(x_{n}, x_{n+1}\right)}{\psi\left(p\left(x_{n}, x_{n+1}\right)\right)} \leq \limsup _{n \rightarrow \infty} \frac{s}{\psi(s)}<\infty,
$$

then $\sum_{1}^{\infty} p\left(x_{n}, x_{n+1}\right)<\infty$. Now by definition of $d_{p}$, we have

$$
d_{p}\left(x_{n}, x_{n+1}\right) \leq 2 p\left(x_{n}, x_{n+1}\right) \rightarrow 0
$$

as $n \rightarrow \infty$, which implies that $\left\{x_{n}\right\}$ is a cauchy sequence in $\left(X, d_{p}\right)$. Since $(X, p)$ is complete, hence $\left(X, d_{p}\right)$ is complete, so we have $\lim _{n \rightarrow \infty} d_{p}\left(x_{n}, x\right)=0$, for some $x \in X$. Now by lemma 1.4 , we get

$$
p(x, x)=\lim _{n \rightarrow \infty} p\left(x_{n}, x\right)=\lim _{m, n \rightarrow \infty} p\left(x_{n}, x_{m}\right)=0 .
$$

Since $X$ has limit comparison property, therefore for $n \in N, x_{n}$ is comparable to $x$, so for $n \in N$, we have,

$$
p\left(x_{2 n+2}, T x\right) \leq \sup _{x \in S x_{2 n+1}} p(x, T x) \leq H_{p}\left(S x_{2 n+1}, T x\right)
$$

Thus,

$$
\begin{aligned}
\psi\left(p\left(x_{2 n+2}, T x\right)\right) & \leq \psi\left(H_{p}\left(S x_{2 n+1}, T x\right)\right) \\
& \leq \psi\left(M\left(x_{2 n+1}, x\right)\right)-\varphi\left(\psi\left(M\left(x_{2 n+1}, x\right)\right)\right) \\
& +\theta\left(p\left(x_{2 n+1}, S x_{2 n+1}\right), p(x, T x), p\left(x_{2 n+1}, T x\right)-p\left(x_{2 n+1}, x_{2 n+1}\right)\right. \\
& \left., p\left(x, S x_{2 n+1}\right)-p(x, x)\right) \\
& \leq \psi\left(M\left(x_{2 n+1}, x\right)\right)-\varphi\left(\psi\left(M\left(x_{2 n+1}, x\right)\right)\right) \\
& +\theta\left(p\left(x_{2 n+1}, x_{2 n+2}\right), p(x, T x), p\left(x_{2 n+1}, T x\right)-p\left(x_{2 n+1}, x_{2 n+1}\right)\right. \\
& \left., p\left(x, x_{2 n+2}\right)-p(x, x)\right)
\end{aligned}
$$

where

$$
p(x, T x) \leq M\left(x_{2 n+1}, x\right)
$$




$$
\begin{aligned}
& =\operatorname{Max}\left\{p\left(x_{2 n+1}, x\right), p\left(x_{2 n+1}, S x_{2 n+1}\right), p(x, T x), \frac{p\left(x_{2 n+1}, T x\right)+p\left(x, S x_{2 n+1}\right)}{2}\right\} \\
& \leq \operatorname{Max}\left\{p\left(x_{2 n+1}, x\right), p\left(x_{2 n+1}, x_{2 n+2}\right), p(x, T x), \frac{p\left(x_{2 n+1}, T x\right)+d\left(x, x_{2 n+2}\right)}{2}\right\} .
\end{aligned}
$$

Letting $n \rightarrow \infty$, then we get $\lim _{n \rightarrow \infty} M\left(x_{2 n+1}, x\right)=d(x, T x)$. Since $\varphi$ is l.s.c, letting $n \rightarrow \infty$ in $(7)$ we get

$$
\psi(p(x, T x)) \leq \psi(p(x, T x))-\varphi(\psi(p(x, T x)))
$$

which implies $\varphi(\psi(p(x, T x)))=0$, and hence $p(x, T x)=0$. Since $T x$ has approximative property, there exist $y \in P_{T x}$ such that $p(y, x)=0$ i.e, $y=x$, therefore $x \in T x$. Thus $x$ is a fixed point of $T$, i.e, $x \in T x$. This completes the proof.

Define $\psi(t)=t$ and $\varphi(t)=(1-k) t$, where $k \in[0,1)$, Then we have the following corollary.

Corollary 2.2 Let $X$ be a complete ordered partial metric space with the limit comparison property. Suppose that $T, S: X \rightarrow 2^{X}$ are two mappings with approximative property and there exist $k \in[0,1)$ such that

$\left.\left.H_{p}(T x, S y)\right) \leq k M(x, y)\right)+\theta(p(x, T x), p(y, S y), p(y, T x)-p(y, y), p(x, S y)-p(x, x))$

for all $x, y \in X$ with $x$ and $y$ comparable and $\psi \in \Psi, \varphi \in \Phi$ and $\theta \in \Theta$. Suppose that $S$ and $T$ are weakly isotone increasing and there exists an $x_{0} \in X$ such that $\left\{x_{0}\right\} \preceq_{2} T x_{0}$. Then $T, S$ have a common fixed point $x \in X$, such that $p(x, x)=0$.

Putting $S=T$ in Theorem 2.1, we obtain the following

Theorem 2.3 Let $X$ be a complete ordered partial metric space with the limit comparison property. Suppose that $T: X \rightarrow 2^{X}$ are generalized $(\psi, \varphi, \theta)$ contractive mappings and have approximative property. Let Tx $\preceq_{2} T(T x)$ for all $x \in X$ and there exists an $x_{0} \in X$ such that $\left\{x_{0}\right\} \preceq_{2} T x_{0}$. Then $T$ have a fixed point $x \in X$, such that $p(x, x)=0$.

Example 2.4 Let $X=\left\{0, \frac{1}{2}, \frac{1}{3}\right\}$ endowed with partial metric $p$ defined by $p(x, y)=\max \{x, y\}$, for all $x, y \in X$. we give the partial order on $X$ by

$$
x \preceq y \Leftrightarrow p(x, x)=p(x, y) \Leftrightarrow x=\max \{x, y\} \Leftrightarrow y \leq x .
$$

It is clear that $(X, \preceq)$ is totally ordered set, and $(X, p)$ is complete partial metric space. we define

$T x=\left\{\begin{array}{ll}\{0\} & \text { if } x \in\left\{0, \frac{1}{3}\right\}, \\ \left\{0, \frac{1}{3}\right\} & \text { if } x=\frac{2}{3},\end{array} \quad\right.$ and $\quad S x= \begin{cases}\{0\} & \text { if } x \in\left\{0, \frac{1}{3}\right\}, \\ \left\{\frac{1}{3}\right\} & \text { if } x=\frac{2}{3} .\end{cases}$

We show that $T$ and $S$ are weakly isotone increasing. Let $y \in S x$ and $z \in S x$. Then $u \in$ Ty implies that $u=0$. Thus $u \leq z$ and so $z \preceq u$. This shows that for any $x \in X$ we have $S x \preceq 2$ Ty for all $y \in$ Sx. Similarly, one can show that for each $x \in X$ we have $T x \preceq_{2}$ Sy for all $y \in T x$.

Let $\psi(t)=t$ and $\varphi(t)=\frac{t}{2}$. It is easy to show that for each $\theta \in \Theta$, the mappings $T, S$ are generalized $(\psi, \varphi, \theta)$ contraction. Now, we can easy to check that all hypotheses of theorem 2.1 are fulfilled. Hence T, S have a common fixed point, which is $x=0$.

\section{References}

[1] I. Altun, F. Sola, H. Simsek, Generalized contractions on partial metric spaces. Topol. Appl. 157, 2778-2785 (2010).

[2] H. Aydi, M. Abbas, C. Vetro, Partial Hausdorff metric and Nadlers fixed point theorem on partial metric spaces. Topol. Appl. 159, 3234-3242 (2012).

[3] C. Di Bari, M. Milojevic, S. Radenovic, P. Vetro, Common fixed points for self-mappings on partial metric spaces. Fixed Point Theory Appl, 2012, 2012: 140. 
[4] B.C. Dhage, D. O'Regan, R.P. Agarwal, Common fixed point theorems for a pair of countably condensing mappings in ordered Banach spaces, J. Appl. Math. Stochastic Anal. 16 (2003) 243-248.

[5] A. Erduran, Common fixed point of $g$ - approximative multivalued mapping in orderred partial metric space. Fixed Point Theory and Applications. 2013 doi:10.1186/1687-1812-2013-36.

[6] S. Hong, Fixed points of multivalued operators in ordered metric spaces with applications Nonlinear Anal., 72 (2010), 3929-3942.

[7] D. Ilic, V. Pavlovic, V.Rakocevic, Some new extensions of Banach's contractions principle in partial metric spaces. Appl Math Lett, 2011, 24: 1326-1330.

[8] D. Ilic, V. Pavlovic, V. Rakocevic, Extensions of Zamfirescu theorem to partial metric spaces. Math Comput Model, 2012, 55: 801-809.

[9] Z. Kadelburg, H. K. Nashine, S. Radenovic, Fixed point results under various contractive conditions in partial metric spaces. RASCAM, 2013, 107(2): 241-256.

[10] S. G. Matthews, Partial metric topology. In: Proceedings of the 8th Summer Conference on General Topology and Applications. Ann. New York Acad. Sci. 728, 183-197 (1994).

[11] H. K. Nashine, Z. Kadelburg, S. Radenovic, J. K. Kim, Fixed point theorems under Hardy-Rogers weak contractive conditions on 0-complete ordered partial metric spaces. Fixed Point Theory Appl. 2012, 180 (2012). doi:10.1186/16871812-2012-180.

[12] H. K. Nashine, Z. Kadelburg, S. Radenovic, Common fixed point theorems for weakly isotone increasing mappings in ordered partial metric spaces. Math Comput Model, 2013, 57(9/10): 2355-2365.

[13] S. Oltra, O. Valero, Banach's fixed point theorem for partial metric spaces. Rend Istit Math Univ Trieste, 2004, 36: 1726 . 